\title{
The trouble with medical journals
}

\author{
Richard Smith
}

J R Soc Med 2006;99:115-119

Richard Smith was editor of the BMJ and chief executive of the BMJ publishing Group for 13 years. In his last year at the journal he retreated to a 15 th century palazzo in Venice to write a book. The book will be published by RSM Press, and the JRSM will be publishing a series of extracts from the book [www.resmpress.co.uk]. This edited introduction sets out his stall.

Medical journals, which many imagine to be as dull as telephone directories and twice as obscure, influence the lives of everybody - and not always for the better. Not only do they affect how doctors treat patients and the actions taken by public health authorities, they also influence how we think about birth, death, pain, and sickness. It may therefore make sense for you-the thoughtful but not necessarily expert reader - to pay attention to the ways of medical journals, particularly as many of those ways are deficient and need reform. That is the thesis of this series of articles.

\section{THE EXPONENTIAL GROWTH IN JOURNALS}

Scientific journals began in the 17th century with the French Journal des Savants and the British Philosophical Transactions of the Royal Society. The journals complemented scientific meetings, which had until then been the main way of communicating science. The history of journals since then has been one in which each new discipline eventually grew tired of simply being part of a larger whole and started its own publication. General medical journals began at the end of the 18th century, and specialist medical journals at the beginning of the 20th century: later in that century came the subspecialty journals. The growth in scientific and medical journals was exponential until a decade or so ago when the whole venture hit the economic buffers.

Some societies and some commercial publishers have grown rich from their journals, earning profit margins of 40\%. They were 'must have' journals, quasi-monopolies. New paper journals ceased to appear in such large numbers a decade or so ago because the traditional business modelof selling subscriptions primarily to institutions - would no longer work.

However, the exponential increase in journals looks set to return now that electronic journals can be started with

London SW1P 1SB, UK

E-mail: richardswsmith@yahoo.co.uk minimal funds. These journals are about the fundamental business of disseminating science rather than making societies or publishers rich.

\section{WHAT ARE JOURNALS FOR AND WHAT ARE THEIR VALUES?}

Some journals have always been about more than publishing science. They have educated, entertained, campaigned, and provided a forum for medical communities to debate issues in depth. I have always been interested in whether journals lead or just simply reflect what is happening in their communities. Using evidence from history and 'media studies' my tentative conclusion is that they can lead-but that they can afford to be a only whisker ahead of those they are attempting to lead.

The values that underpin journals are almost always implicit rather than explicit. Medical journals are a confluence of medicine, science and journalism - and might be expected to have the values of all three. Sometimes, however, these values conflict. The values of both science and journalism, for example, might favour publication of a weak study with a conclusion that could cause a 'scare' among the pubic - because publication and debate are fundamental values to both. In contrast, medical values, which put a strong emphasis on 'doing no harm', might favour waiting until stronger evidence emerged.

\section{THE POOR SCIENCE OF MEDICAL JOURNALS}

The science that underpins medicine is presented in journals, and most journals can point to landmark studies that changed medicine. The BMJ, for example, published some of the first studies in anaesthesia, on the cause of malaria, and on linking cigarettes to lung cancer. It also published one of the first randomized controlled trial, which scientifically was a major development. The journals might also be said to have become 'more scientific' over the years as the rigour of the methods of the studies they publish has improved.

Yet medical journals often contain poor science. Basic scientists who work in biology and chemistry are regularly scornful of the, mostly, applied science that appears in medical journals. The journals have, for example, published many reports of treatments applied to single cases and to series of cases, which rarely allow confident conclusions because of the absence of controls. Journals have also been 


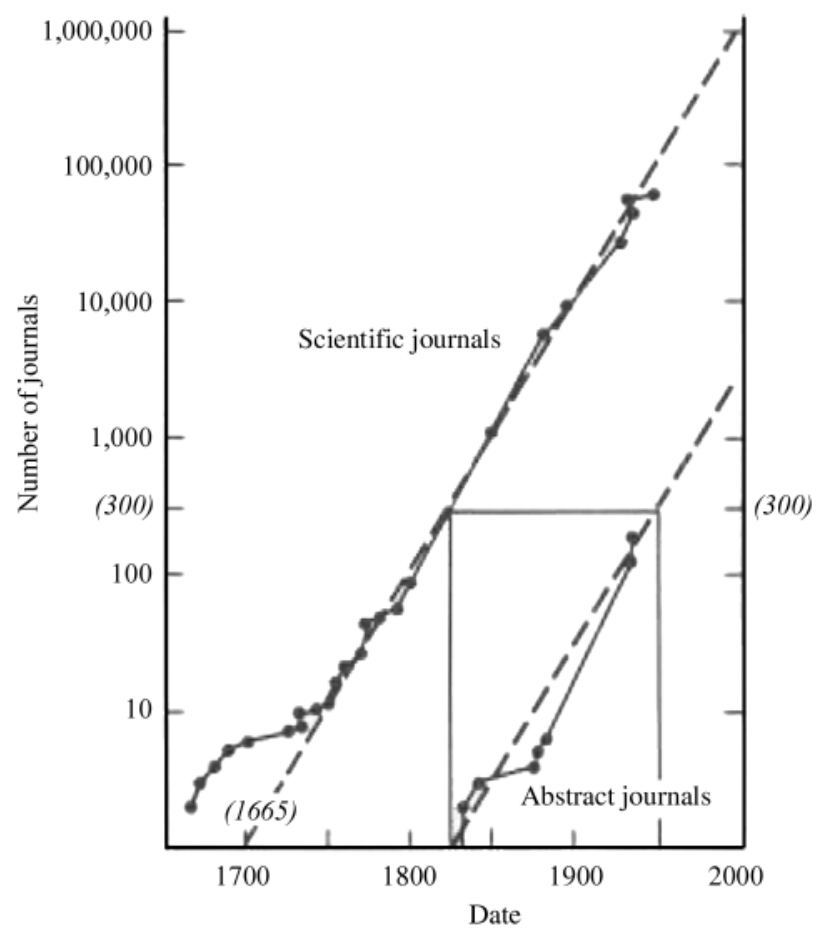

Figure 1 Total number of scientific journals and abstract journals founded, as a fraction of date

Note that abstracts begin when the population of journals is approximately 300. Numbers recorded here are for journals founded, rather than those surviving for all periodicals containing any "science" rather than for "strictly scientific" journals. Tighter definitions might reduce the absolute numbers by an order of magnitude but the general trend remains constant for all definitions. [From Derek J. de Solla Price, Science Since Babylon. New Haven: Yale University Press, 1961]

part of what might be called an 'unscientific' method of encouraging treatments that seem to make anatomic, physiological, or biochemical sense, without insisting that they be properly evaluated in practice.

The history of medicine is littered with treatments that seemed to make sense but which ultimately did more harm than good. Sir Arbuthnot Lane, who was mercilessly parodied in George Bernard Shaw's The Doctor's Dilemma, removed the colons of Londoners who were severely fatigued and rich enough to meet his high fees. The operation was supposedly removing toxins. A tenth of his patients were killed by the operation. I belong to a generation who had their tonsils removed to no benefit. While my wife, when having our first child in 1982, was given an enema and had her pubic hair shaved-procedures which are unpleasant and of no benefit.

Medicine itself probably deserves most criticism for its unscientific behaviour but journals are the major link between science and practice. In recent year, journals have scientifically weak (in that their conclusions are not supported by their methods and data) and irrelevant to practitioners (and so patients).

\section{PEER REVIEW: MORE EVIDENCE OF HARM THAN BENEFIT}

Peer review - i.e. asking peers of the authors of scientific studies to review the studies critically before publicationis the process that is supposed to ensure the scientific quality of journals. It is a sacred process - and the phrase 'peer reviewed journal' is supposed to guarantee quality. But clearly peer review is deficient. Despite being central to the scientific process it was itself largely unstudied until various pioneers - including Stephen Lock, former editor of the $B M J$, and Drummond Rennie, deputy editor of JAMAurged that it could and should be studied. Studies so far have shown that it is slow, expensive, ineffective, something of a lottery, prone to bias and abuse, and hopeless at spotting errors and fraud. The benefits of peer review have been much harder to establish. As Rennie says, 'If it was a drug it would never get onto the market'. Nevertheless, no journal would dare to abandon peer review. Editors are convinced-even though they are finding it had to prove- that peer review is invaluable.

\section{SCIENCE FOR THE UNSCIENTIFIC}

Medical journals differ from scientific journals in that they are mainly read not by scientists but by practising doctors. But are not doctors also scientists? We are, in that when we were medical students our heads were filled with anatomy, biochemistry, physiology and (if we are under 40) by molecular biology; but such teaching does not a scientist make. Most doctors feel uncomfortable describing themselves as scientists. Most are not even trained to appraise critically a scientific article.

Why then are they sent journals filled with increasingly complex science, most of which depends on statistical methods that they do not understand? It is, I think, a historical hangover, and there are lots of data to show that doctors spend little time reading the original research in journals. They are sensible not to do so. The average doctor spends not much more than an hour a week on professional reading. Thus, it does not make sense to spend most of that time reading one complex study. Doctors, sensibly, should read synoptic, educational material; mostly that is what doctors do. Often they read this material not in journals but in what are condescendingly known as 'throwaways', i.e. newspapers that use journalists to summarize complex material and which are free because they are funded by pharmaceutical advertising. 


\section{TRYING TO BE MORE USEFUL}

Journals have long recognized that they are unlikely to flourish if they publish only scientific studies. Increasingly they publish reviews that update practitioners on new developments, educational material, news, reviews of books, articles that are more journalism than science, letters and obituaries. Slowly they have begun to look less like traditional scientific journals and more like popular magazines with shorter articles, brief summaries, and graphics.

They try to be useful tools to doctors in their practice, but they have had only limited success. Doctors suffer from what Muir Gray, a public health doctor and director of Britain's National Electronic Library of Health, calls 'the information paradox': they are overwhelmed with material of limited relevance and quality but cannot find answers to the many questions that arise when they meet with patients and which thus go unanswered. Journals are not good at getting doctors to change and improve their practice. Words on paper rarely lead directly to change.

What journals can do is to make people think, set agendas, encourage debate, draw doctors' attention to new things that may be important, and even legitimize subjects. In short, they are very like newspapers, and Robbie Fox, the great editor of the Lancet in the 20th century, liked to call his journal a newspaper.

Should journals then abandon publishing science? In the end science might abandon them and be posted on publicly available websites rather than appear in journals; but it is unlikely that many journals will abandon science first (although I can think of at least one American journal of family practice that has done so). Most of a journal's kudos comes from the science it publishes; it is the science rather than the rest of the material that attracts worldwide media attention and causes subscribers (mostly institutions) to purchase the journals. Some of the scientific studies that journals publish are hugely important, and the science gives journals an authority and legitimacy that separates them from the (usually much more readable) 'throwaways'.

Despite my criticisms of journals I still believe that a good journal can be a major asset to a medical community. It can move medicine forward, less by providing a clear direction of travel and more through highlighting the deficiencies of the present - and providing a hundred ideas on how to do better.

\section{MEDICAL JOURNALS AND PATIENTS}

But do journals benefit patients? Medical journals are intended for doctors not patients. Any benefit to patients would come from improvements in their doctors. Now, with the arrival of the internet, patients can access the same information as doctors; sometimes the patient is better informed than the doctor. This is a new world for both doctors and patients, but there is growing evidence that doctors and patients taking decisions together - rather than doctors taking decisions on behalf of patients - leads to patients doing better and feeling more satisfied.

Even if patients have not been readers of medical journals, they have certainly featured in their pages. As recently as 10 years ago journals might publish pictures of patients naked without them knowing a thing about it. Now journals are moving into a world where they have patients on editorial boards and even editors who are patient not doctors. Journals are trying to move from a world where patients were objects to one where they are partners. But here I judge journals are lagging behind the practice of medicine.

\section{FAILURE TO DEAL WITH CONFLICTS OF INTEREST}

Medical journals have failed to effectively manage conflicts of interest. Until very recently journals did not ask authors and reviewers about conflicts of interest. But most authors in medical journals do have financial conflicts of interest, particularly in their relations with pharmaceutical companies. These undeclared conflicts of interest can have profound effects on the studies undertaken and the conclusions they reach. On some major issues-like whether passive smoking is harmful or whether third generation contraceptive pills are more likely to cause clots in the legs and lungs than earlier pills - authors linked to the manufacturers reach completely different conclusions from those who are not. So journals have to do a better job at managing conflict of interest. This does not mean the complete avoidance of papers written by authors with conflicts of interest; such conflicts are inevitable and all pervasive.

\section{MEDICAL JOURNALS ARE TOO CLOSE TO PHARMACEUTICAL COMPANIES}

Most journals also face an ethical problem in being so closely associated with pharmaceutical companies. These companies are important in that almost all the new drugs of the past 50 years that have transformed medicine have been discovered or developed by them. But the interests of pharmaceutical companies and doctors, patients, and therefore journals (that should put doctors and patients first) are not always the same. A company might want patients to take its drug even though another drug might be better. Companies will push drug rather than non-drug treatments, even though for many conditions - e.g. diabetes - non-drug treatments are often more important.

Some journals have been captured by pharmaceutical companies because they have come to depend on them. 
Many, including some of the most prestigious journals, publish mostly trials that are funded by the industry. The results of these trials are rarely unfavourable to the companies. The journals depend on income from advertising and sales of reprints (a company might pay over $\$ 1 \mathrm{~m}$ for reprints of one study, which it funded in the first place). Journals should not attempt to separate themselves from pharmaceutical companies, but the relationship should be more ethically sound.

\section{LOVE AND HATE RELATIONSHIP WITH THE MEDIA}

Some would also argue that journals have an unhealthy relationship with the mass media. Indeed, they might be degenerating to a branch of show business. Our competitors, I told my staff at the BMJ, were not just the New England Journal of Medicine and the Lancet but Hollywood films and Manchester United. I meant that we were part of the 'attention economy' and that we competed all the time with a rich variety of pleasures for the attention of doctors. I did not mean that we should abandon our fundamental principles and seek publicity at any price; but there is no doubt that coverage in the mass media is good for journals in both prestige and business terms. All the major journals put out press releases (and some in the USA even put out video clips) and are disappointed if an issue does not receive any coverage. Sometimes, there will be global coverage. But are journals debasing ourselves in pursuit of publicity?

\section{RESEARCH FRAUD}

Sometimes journals receive coverage in the media that makes them squirm, particularly when they are exposed as having published research that is fraudulent. Fraud in science is as old as science itself-because science is a human activity. But fraud was not high on anybody's agenda until about 20 years ago. As recently as 5 years ago I heard a fellow of the Royal Society argue that fraud was exceedingly rare, did not happen with 'proper scientists', had never harmed anybody, and did not matter because science was self correcting. It is now impossible to take this position in public, as there are an increasing number of examples of fraud. In one phone call in December 2002 I had to tell the editor of the Lancet that I had compelling evidence that two major trials he had published were fraudulent.

Some countries - particularly the USA and the Nordic countries - have mounted a coherent response to scientific fraud; but most countries, including Britain, have not. Medical editors in Britain have created the Committee on Publication Ethics, a sort of self-help group for responding to fraud - or as it is better called 'research misconduct'. (Fraud is a severe word to use for much of the comparatively minor forms of misconduct that seem to be common - and has connotations of financial fraud.) COPE started in 1997 and has now dealt with about 250 cases. For some it has caused a transformation in how they deal with misconduct. Whereas editors were inclined to look the other way (especially as most of the problems arose in studies they had no intention of publishing), many now feel an obligation to act. This transformation is similar to what has happened in medicine itself, where regulatory bodies will discipline doctors who fail to act on signals of clinical, research, or financial misconduct.

However, I still feel that editors after all are at the beginning of the process of the response to research misconduct. Some editors are not sensitized to the problem. Most of COPE's cases come from a few journals, and it is impossible to believe that those journals have many problems while others have none. Even when editors do decide that they need to respond to problems, they are often unclear what action to take. And even when they do alert universities or other employers to the possibility of misconduct, these establishments either will not or cannot take action. I worry that journals are being polluted by misconduct and that editors are not responding adequately.

\section{FROM AUTHORSHIP TO CONTRIBUTORSHIP}

Jane Austen wrote every word of her novels and was indisputably the author of her books. But conducting scientific research often depends on large teams of people with different skills. Deciding who should be listed as an author is not simple, and too often the decision is made on the basis of power. The powerful are included, even when they have done nothing, and the weak are excluded, even those who have done most of the work. This unethical behaviour can become a major problem if the study proves to be fraudulent, as has happened many times. For authorship implies not just credit, which authors love, but also accountability, about which they are much less enthusiastic. Senior authors suddenly say that they cannot be held responsible for a corrupted study because they had nothing to do with it. Such a position does not impress. One radical but rational response to the problem of authorship is to abandon the idea within science. Instead, we should go for contributorship, where the contribution of everybody is simply described, rather as with film credits.

\section{REDUNDANT PUBLICATION}

One form of misconduct that seems minor at first is publishing the same study — or large parts of it - more than once. This is irritating but surely not serious. It so happens, however, that studies that find a treatment, often a drug, to be effective tend to be published more than once, whereas those studies that find that the treatment does not work are 
often not published at all. The result is a systematic bias in medical information that makes some treatments seem much more effective than they actually are. Patients are then mistreated.

\section{JOURNALS ARE RIPPING OFF ACADEMICS}

Many of the problems of medical journals are problems of medicine, but the problem of ripping off authors lies squarely with journals. 'All publishing is theft', the BMA's librarian used to joke - before he left to join Reed-Elsevier, the world's most profitable publisher of science, giving an ironic twist to his joke. As somebody who was something to do with publishing I was offended when I first heard this phrase. But more to the point I did not understand. Now I do.

Most medical journals comprise almost entirely research articles. These articles are written by the researchers and submitted to the journals for free. Consider the value in a major trial published in a medical journal. Such trials can costs millions of pounds to conduct. Almost all of the value is in the trial itself. (By 'value' I mean the unique contribution that customers are willing to pay for.) Most of these trials are conducted by academics, and many are funded with public money. The journals conduct peer review, but I have already argued that this is a process that adds little value. What is more, the peer review is usually done by academics without pay. Indeed, many journals are edited by unpaid academics. Often it is academics, again unpaid, who edit the studies before they are published. The journals are then sold to academic libraries - and often at huge prices. An annual subscription to some journals may be over $\$ 20000$. Publishers - sometimes commercial companies, although often medical or scientific organizations - make substantial profits, but without adding much value. Indeed, publishers may subtract value by Balkanizing the scientific literature, severely limiting accessibility.

Robert Maxwell, a publisher of newspapers and journals who became famous for stealing his employees' pension fund, got rich through publishing scientific journals. The ethics of the business of scientific publishing are highly suspect.

\section{INCREASING THE PROBITY OF RESEARCH AND THE ACCOUNTABILITY OF EDITORS}

Descriptions of highly unethical medical research conducted after the second world war led to the creation of research ethics committees (or institutional review boards in the USA). Across the globe these committees are now proving to be overworked, under-resourced, and insufficiently skilled. Radical reform is needed as they are impeding rather than simply regulating research. Medical journals have also been poor at ensuring the ethical acceptability of what they are publish _ often failing to ensure that research has had approval from research ethics committees. But journals sometimes identify failings in the research ethics committees, and I believe that the committees and journals might work more creatively together.

But what about the accountability of journals and their editors? The Lancet took the bold step of introducing an ombudsman to consider complaints against the editors. The experiment seems to have been a success but has not been widely copied. The BMJ introduced an ethics committee of its own, and almost immediately wondered how it managed for 160 years without one. But these are small experiments. Most journals have neither an ombudsman nor an ethics committee. Much more needs to be done to improve the ethical accountability of editors and journals.

Medical journals, just like any other publications, are covered by the laws of libel. In Britain these are strict, and the $B M J$ was involved in one of the longest running libel cases in British legal history. The law of libel has to balance injury to individuals against freedom of speech. British law is tipped towards the individual, American law towards freedom of speech. Unsurprisingly, I would like British law to move in the American direction.

Sir Richard Peto, one of Britain's most distinguished medical researchers, says that concern with ethical issues in publishing medical research is causing more harm than good. The problem, he argues, is minor, but clamour around the problem is making research much harder to do. The result is that the public is harmed rather than benefited-because so many of medicine's questions are unanswered and research is badly needed.

\section{CONCLUSION}

I am proud to have been part of such an energetic, exciting, and, I hope, ultimately useful enterprise as the publishing of journals, but I'm concerned that much of what journals do is ethically weak. This series will explores some of these concerns in more detail, searching always for possible means to do better.

I've left references out of this introductory article, but the statements I've made are fully referenced in the relevant articles and chapters. Furthermore, many of the topics that I cover in the book I have written about in the BMJ and other publications. The book makes clear where material has already been published. 